\title{
Synthesis of Aromatic Polydithioacetals from Aromatic Dithiol and Aromatic Aldehydes by Using Poly- phosphoric Acid Trimethylsilyl Ester
}

\author{
Masa-aki KaKImoto, Takuya Seri, and Yoshio IMAI* \\ Department of Organic and Polymeric Materials, Tokyo Institute \\ of Technology, Meguro-ku, Tokyo 152, Japan
}

(Received May 15, 1987)

\begin{abstract}
Aromatic polydithioacetals having inherent viscosities of $0.12-0.24 \mathrm{dl} \mathrm{g}^{-1}$ were synthesized by the solution polycondensation of $4,4^{\prime}$-oxydibenzenethiol with aromatic aldehydes in the presence of polyphosphoric acid trimethylsilyl ester as a condensing agent. These polymers are soluble in a variety of solvents including dimethylformamide, tetrahydrofuran, chloroform, and benzene. They are less thermally stable polymers, and start to decompose above $200^{\circ} \mathrm{C}$ in air, with $10 \%$ weight losses being recorded at $260-270^{\circ} \mathrm{C}$ on the thermogravimetry curves.

KEY WORDS Aromatic Polydithioacetals / Polyphosphoric Acid Trimethylsilyl Ester / Solubility / Thermal Behavior /
\end{abstract}

Recently Polyphosphoric acid trimethylsilyl ester (PPSE), which is prepared readily starting from phosphorus pentoxide and hexamethyldisiloxane, has attracted considerable attention as a unique condensing agent in the field of synthetic organic chemistry. ${ }^{1}$ Our previous works have dealt with the direct synthesis of various amidines in the presence of PPSE by the reaction of aromatic amines with carboxylic acids, ${ }^{2,3}$ and its application to the synthesis of aromatic polyamidines. ${ }^{4}$

Quite recently, we found that various dithioacetals were obtained in excellent yields from the PPSE-mediated condensation of thiols with aldehydes or ketones. ${ }^{5}$ In this article, we report a novel method for the synthesis of aromatic polydithioacetals by successful extension of the dithioacetal formation to aromatic dithiol-aldehyde monomer pairs (eq 1).

Although a variety of polyacetals has been known for many years, ${ }^{6}$ the analogous poly- dithioacetals have been reported only sparingly to date. Marvel et al. reported the preparation of aliphatic polydithioacetals by the hydrogenchloride-catalyzed polycondensation of aliphatic dithiols with aldehydes. ${ }^{7}$

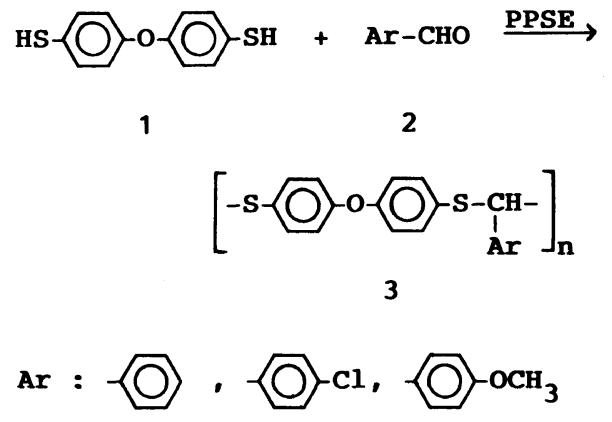

\section{EXPERIMENTAL}

\section{Materials}

4,4'-Oxydibenzenethiol (1) was prepared according to the method of Baron and Blank ${ }^{8}$ in

\footnotetext{
* To whom all correspondence should be addressed.
} 
$60 \%$ yield by the stannous chloride reduction of 4,4'-oxydi(benzenesulfonyl chloride); $\mathrm{mp}$ $103-104^{\circ} \mathrm{C}\left(\right.$ lit. $\left.^{8} \mathrm{mp} 103-104^{\circ} \mathrm{C}\right)$.

Aromatic aldehydes such as benzaldehyde (2a), p-chlorobenzaldehyde (2b), and $p$-anisaldehyde (2c), and all the solvents used were purified by distillation.

\section{Polymerization}

Polymer 3a. PPSE was prepared by the reaction of $1.42 \mathrm{~g}(5.00 \mathrm{mmol})$ of phosphorus pentoxide and $1.62 \mathrm{~g}(10.0 \mathrm{mmol})$ of hexamethyldisiloxane in $5 \mathrm{ml}$ of 1,2-dichloroethane with stirring at $40^{\circ} \mathrm{C}$ for $1 \mathrm{~h}$ under nitrogen. To the solution were added $1.17 \mathrm{~g}$ $(5.00 \mathrm{mmol})$ of 1 and $0.53 \mathrm{~g}(5.00 \mathrm{mmol})$ of $2 \mathrm{a}$, and the mixture was heated with stirring at $80^{\circ} \mathrm{C}$ for $5 \mathrm{~h}$ under nitrogen. During this period, the polymer precipitated out of the solution. The reaction mixture was then poured into $300 \mathrm{ml}$ of $1 \mathrm{M}$ aqueous sodium hydroxide. The precipitated polymer was collected, and washed successively with the dilute alkaline solution and hot methanol. The product was purified by two repeated reprecipitations from tetrahydrofuran (THF) with aqueous methanol. The yield was $1.56 \mathrm{~g}$ $(97 \%)$. The inherent viscosity of the polymer in dimethylformamide (DMF) was $0.24 \mathrm{dl} \mathrm{g}^{-1}$, measured at a concentration of $0.5 \mathrm{~g} \mathrm{dl}^{-1}$ at $30^{\circ} \mathrm{C}$. The IR spectrum (KBr) exhibited a characteristic absorption at $1230 \mathrm{~cm}^{-1}(\mathrm{C}-$ $\mathrm{O}-\mathrm{C})$. The ${ }^{1} \mathrm{H}$ NMR spectrum $\left(\mathrm{CDCl}_{3}\right.$ solution) showed peaks at $5.3 \mathrm{ppm}(\mathrm{s}, 1 \mathrm{H}, \mathrm{CH})$ and $6.7-7.4 \mathrm{ppm}(\mathrm{m}, 13 \mathrm{H}$, aromatic $\mathrm{H})$. Anal. Calcd for $\left(\mathrm{C}_{19} \mathrm{H}_{14} \mathrm{OS}_{2}\right)_{n}: \mathrm{C}, 70.77 \% ; \mathrm{H}$; $4.38 \%$ S, $19.89 \%$. Found: C, $70.86 \%$; $4.39 \%$; S, $19.64 \%$.

\section{Measurements}

IR and ${ }^{1} \mathrm{H}$ NMR spectra were recorded on a Hitachi EP-G3 spectrophotometer and a JEOL JNM-PMX60NMR spectrometer $(60 \mathrm{MHz})$, respectively. DTA and TG were performed with Shimadzu thermal analyzers DTA-30M and TGA-30M, respectively.

\section{RESULTS AND DISCUSSION}

\section{Polymer Synthesis}

The high-yield reaction of benzenethiol with various aldehydes giving dithioacetal compounds ${ }^{5}$ was applied to polymer synthesis. The conditions for the PPSE-promoted polycondensation of $\mathbf{1}$ with $\mathbf{2 a}$ in 1,2-dichloroethane were first examined in detail in order to obtain polymer 3a with high molecular weight.

Figure 1 shows the effect of amount of PPSE on the inherent viscosity of the polymer. The use of an equal amount of PPSE was found to be essential for the preparation of the polymer with the highest viscosity, and the use of an excess amount of PPSE also gave satisfactory results.

Figure 2 indicates the effect of monomer concentration on the polycondensation. Monomer concentration had a significant influence on the inherent viscosity of the resulting polymer, reaching a maximum at the concentration of $0.5 \mathrm{mmol} \mathrm{g}^{-1}$. It is frequently observed in the polycondensation reactions that the monomer concentration has the optimum value.

The effect of reaction temperature on the polymerization is shown in Figure 3. Reaction temperatures also greatly influenced the inherent viscosity of the polymer, which reached

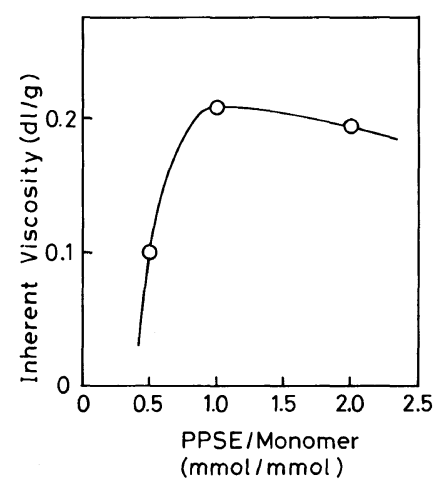

Figure 1. Effect of the amount of PPSE on inherent viscosity of polymer 3a formed by the polycondensation at $80^{\circ} \mathrm{C}$ for $5 \mathrm{~h}$ at the monomer concentration of 0.25 $\mathrm{mmol} \mathrm{g}^{-1}$ in 1,2-dichloroethane. 


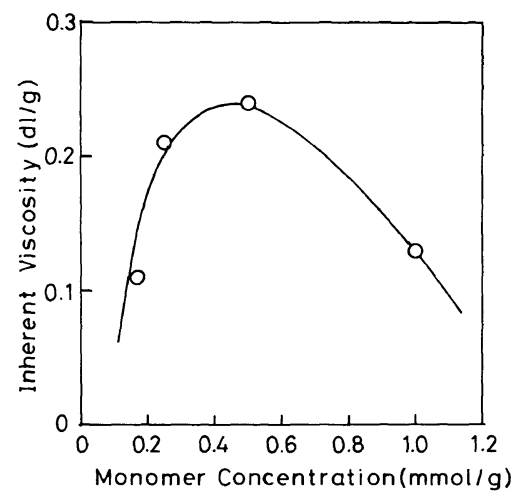

Figure 2. Effect of monomer concentration on inherent viscosity of polymer 3a formed by the polycondensation in 1,2-dichloroethane at $80^{\circ} \mathrm{C}$ for $5 \mathrm{~h}$.

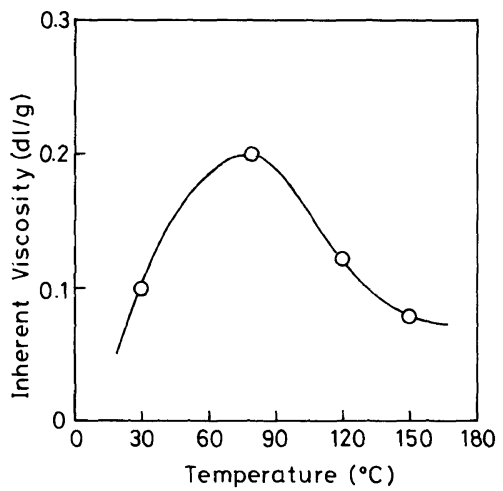

Figure 3. Effect of reaction temperature on inherent viscosity of polymer 3a formed by the polycondensation for $5 \mathrm{~h}$ at the monomer concentration of $0.5 \mathrm{mmol} \mathrm{g}^{-1}$ in sym-tetrachloroethane.

a maximum at the temperature of $80^{\circ} \mathrm{C}$. A lower temperature around $30^{\circ} \mathrm{C}$ might retard the polycondensation, while higher temperatures above $120^{\circ} \mathrm{C}$ induced a thermal decomposition or other side reactions, evident through the actual discoloration of the reaction mixture.

Table I summarizes the solvent effect on the polycondensation. All the solvents used were effective for the preparation of the polymer having reasonable inherent viscosities. Among them, 1,2-dichloroethane afforded the polymer with the highest viscosity.

Figure 4 indicates the course of the polycon-
Table I. Effect of solvent on inherent viscosity of polymer $3 \mathbf{a}^{\mathbf{a}}$

\begin{tabular}{lccc}
\hline \multirow{1}{*}{ Solvent } & Yield & & $\eta_{\text {inh }}{ }^{\mathrm{b}}$ \\
\cline { 2 - 3 } & $\%$ & & $\mathrm{dlg}^{-1}$ \\
\hline 1,2-Dichloroethane & 97 & 0.24 \\
sym-Tetrachloroethane & 98 & 0.20 \\
Toluene & 99 & 0.17 \\
Nitrobenzene & 96 & 0.20 \\
Tetramethylene sulfone & 99 & 0.20 \\
\hline
\end{tabular}

a Polymerization was carried out with $5.0 \mathrm{mmol}$ of 1 and $5.0 \mathrm{mmol}$ of $2 \mathrm{a}$ in $5.0 \mathrm{mmol}$ of PPSE and $5.0 \mathrm{ml}$ of the solvent at $80^{\circ} \mathrm{C}$ for $5 \mathrm{~h}$.

b Measured at a concentration of $0.5 \mathrm{~g} \mathrm{dl}^{-1}$ in DMF at $30^{\circ} \mathrm{C}$.

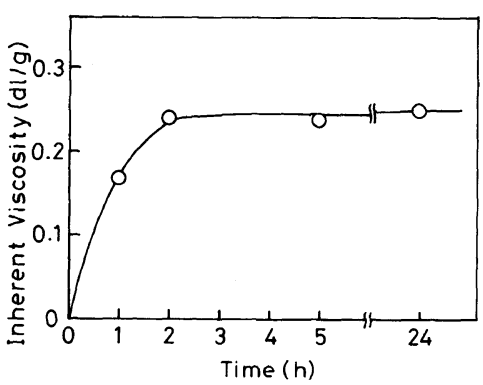

Figure 4. Time dependence of inherent viscosity of polymer 3a formed by the polycondensation at $80^{\circ} \mathrm{C}$ at the monomer concentration of $0.5 \mathrm{mmol} \mathrm{g}^{-1}$ in $1,2-$ dichloroethane.

densation in terms of the inherent viscosity of the polymer. The polymerization proceeded fairly rapidly at $80^{\circ} \mathrm{C}$, and was almost completed in $2 \mathrm{~h}$. The reaction mixture was clear at the first stage, and soon the polymer was separated from the solution as a white gel under the conditions.

The polycondensations of $\mathbf{1}$ with $\mathbf{2 b}$ and $\mathbf{2 c}$ giving $\mathbf{3 b}$ and $\mathbf{3 c}$, respectively, were conducted under the optimum reaction conditions determined in the preparation of $3 \mathbf{a}$ from $2 \mathbf{a}$. As summarized in Table II, the PPSE-promoted polymerization afforded readily polydithioacetals $3 \mathbf{a}-\mathbf{3} \mathbf{c}$ having inherent viscosities of $0.12-0.24 \mathrm{dlg}^{-1}$; however, the polymers with sufficiently high molecular weights could not be obtained. 
Table II. Synthesis of aromatic polydithioacetals ${ }^{\mathrm{a}}$

\begin{tabular}{cccc}
\hline & \multicolumn{3}{c}{ Polymer } \\
\cline { 2 - 4 } Aldehyde & & Yield & $\eta_{\text {inh }}{ }^{\mathrm{b}}$ \\
\cline { 2 - 4 } & Code & $\frac{0}{\mathrm{dlg}^{-1}}$ \\
\hline 2a & 3a & 97 & 0.24 \\
2b & 3b & 84 & 0.12 \\
2c & 3c & 90 & 0.14 \\
\hline
\end{tabular}

a Polymerization was carried out with $5.0 \mathrm{mmol}$ of $\mathbf{1}$ and $5.0 \mathrm{mmol}$ of 2 in $5.0 \mathrm{mmol}$ of PPSE and $5.0 \mathrm{ml}$ of $1,2-$ dichloroethane at $80^{\circ} \mathrm{C}$ for $5 \mathrm{~h}$.

b Measured at a concentration of $0.5 \mathrm{~g} \mathrm{dl}^{-1}$ in DMF at $30^{\circ} \mathrm{C}$.

The structures of the polymers formed were confirmed by means of IR and ${ }^{1} \mathrm{H}$ NMR spectroscopy and elemental analysis. In the IR spectra of the polymers, both an absorption at $2555 \mathrm{~cm}^{-1}$ due to thiol function of dithiol 1 and a characteristic carbonyl absorption at $1700 \mathrm{~cm}^{-1}$ of aldehydes 2 entirely disappeared. In the ${ }^{1} \mathrm{H}$ NMR spectra, a peak at $5.3 \mathrm{ppm}$ due to methine proton of the polymers appeared with the disappearance of a peak at $3.4 \mathrm{ppm}$ due to thiol proton of the dithiol. The elemental analysis values were in good agreement with the calculated values of the polymers. Thus, the polymers obtained were identified as the proposed dithioacetal polymers shown in eq 1.

\section{Polymer Characterization}

The aromatic polydithioacetals dissolved readily in a variety of solvents such as DMF, dimethyl sulfoxide, pyridine, tetrahydrofuran, chloroform, and benzene at room temperature or on heating. They were insoluble in methanol and hexane. Although the polymers were of relatively low molecular weights, this high solubility behavior is probably attributed to the existence of bulky pendant phenyl group.

The thermal behavior of the polymers was evaluated by means of DTA and TG. Figure 5 shows the thermograms for polymer $3 a$.

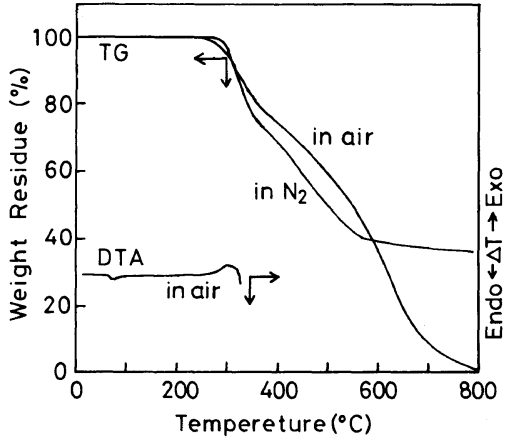

Figure 5. DTA and TG curves of polymer 3a at a heating rate of $10 \mathrm{~K} \mathrm{~min}^{-1}$.

All the polymers started to decompose above $200^{\circ} \mathrm{C}$ in air, and $10 \%$ weight losses were recorded on the TG curves at 260$270^{\circ} \mathrm{C}$ and $300-310^{\circ} \mathrm{C}$ under air and nitrogen, respectively. Thus, the aromatic polydithioacetals were found to be less thermally stable than the aromatic polyformals derived from bisphenols and dichloromethane, ${ }^{9}$ and even than the aliphatic polysulfides from aliphatic dithiols and dibromoalkanes. ${ }^{10}$ This thermal instability may be explained by the existence of a dithioacetal group in the polymer backbones. ${ }^{11}$ On each DTA curve, a small endothermic peak, presumably due to glass transition temperature of the polymer, was observed at a $70-90^{\circ} \mathrm{C}$ temperature range.

\section{REFERENCES}

1. T. Imamoto, J. Synth. Org. Chem. Jpn., 43, 1163 (1985).

2. M. Kakimoto, S. Ogata, A. Mochizuki, and Y. Imai, Chem. Lett., 821 (1984).

3. S. Ogata, A. Mochizuki, M. Kakimoto, and Y. Imai, Bull. Chem. Soc. Jpn., 59, 2171 (1986).

4. S. Ogata, M. Kakimoto, and Y. Imai, Makromol. Chem., Rapid Commun., 6, 835 (1985).

5. M. Kakimoto, T. Seri, and Y. Imai, Synthesis, 164 (1987).

6. S. R. Sandler and W. Karo, "Polymer Synthesis," Vol. II, Academic Press, New York, N. Y., 1977, pp 171-231.

7. C. S. Marvel, W. H. H. Shen, and R. R. Chambers, $J$. Am. Chem. Soc., 72, 2106 (1950). 
8. A. L. Baron and D. R. Blank, Makromol. Chem., 140, 83 (1970).

9. A. S. Hay, F. J. Williams, H. M. Relles, and B. M. Boulette, J. Macromol. Sci.-Chem., A21, 1065 (1984).
10. M. Ueda, Y. Oishi, N. Sakai, and Y. Imai, Macromolecules, 15, 248 (1982).

11. S. Patai, "The Chemistry of the Thiol Groups," Part 2, John Wiley \& Sons, New York, N. Y., 1974, p 716. 